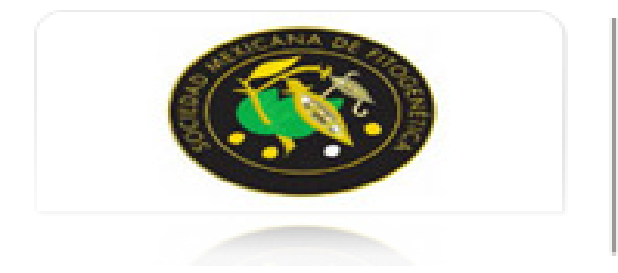

Revista Fitotecnia Mexicana

ISSN: 0187-7380

revfitotecniamex@gmail.com

Sociedad Mexicana de Fitogenética, A.C.

México

Vera Guzmán, Araceli M.; Santiago García, Patricia A.; López, Mercedes G. COMPUESTOS VOLÁTILES AROMÁTICOS GENERADOS DURANTE LA ELABORACIÓN DE MEZCAL DE Agave angustifolia Y Agave potatorum

Revista Fitotecnia Mexicana, vol. 32, núm. 4, octubre-diciembre, 2009, pp. 273-279 Sociedad Mexicana de Fitogenética, A.C.

Chapingo, México

Disponible en: http://www.redalyc.org/articulo.oa?id=61011789003

- Cómo citar el artículo

Número completo

- Más información del artículo

- Página de la revista en redalyc.org

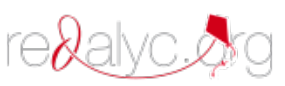

Sistema de Información Científica

Red de Revistas Científicas de América Latina, el Caribe, España y Portugal Proyecto académico sin fines de lucro, desarrollado bajo la iniciativa de acceso abierto 


\title{
COMPUESTOS VOLÁTILES AROMÁTICOS GENERADOS DURANTE LA ELABORACIÓN DE MEZCAL DE Agave angustifolia Y Agave potatorum
}

\author{
AROMATIC VOLATILE COMPOUNDS GENERATED DURING MEZCAL PRODUCTION FROM \\ Agave angustifolia AND Agave potatorum
}

\author{
Araceli M. Vera Guzmán ${ }^{1 *}$, Patricia A. Santiago García ${ }^{1}$ y Mercedes G. López²
}

\begin{abstract}
${ }^{1}$ Centro Interdisciplinario de Investigación para el Desarrollo Integral Regional, Unidad Oaxaca, Instituto Politécnico Nacional (CIIDIR-IPN-Oaxaca). Calle Hornos 1003. 71230, Sta. Cruz Xoxocotlán, Oaxaca. Tel y fax: 01 (951) 5170610 ext. $82752 .{ }^{2}$ Centro de Investigación y de Estudios Avanzados del IPN, CINVESTAV-Unidad Irapuato. Km. 9.6 Libramiento Norte de la carretera Irapuato-León. 36500, Irapuato, Guanajuato, México.
\end{abstract}

* Autor para correspondencia (araverag@yahoo.com.mx)

\section{RESUMEN}

En este trabajo se evaluaron los principales compuestos volátiles aromáticos mayoritarios generados durante el cocimiento, la fermentación de mostos y su permanencia en el producto final (mezcal) de las especies Agave angustifolia Haw. y A. potatorum Zucc. destilados con el sistema tradicional del Estado de Oaxaca, México. La identificación y cuantificación de compuestos volátiles se hizo por cromatografía de gases, con columnas capilares y estándares puros. Los volátiles mayoritarios presentes desde los agaves cocidos hasta los productos finales fueron: metanol, etanol y ácido acético, mientras que 2-metil-1-propanol y 3-metil-1-butanol se produjeron a partir de la fermentación y alcanzaron concentraciones de 39 y $140 \mathrm{mg} \mathrm{L}^{-1}$ en el mosto de $A$. angustifolia y de 40 y $121 \mathrm{mg} \mathrm{L}^{-1}$ en el de $A$. potatorum. La composición de volátiles fue diferente entre los dos mezcales; el de $A$. angustifolia presentó mayores contenidos de metanol, alcoholes superiores y ácido acético que el mezcal de $A$. potatorum.

Palabras clave: Agave angustifolia, A. potatorum, mezcal, volátiles.

\section{SUMMARY}

In this study the aromatic volatile compounds in cooked pines, wort, and mezcal from Agave angustifolia Haw. and A. potatorum Zucc., processed with the traditional artisan production system of Oaxaca, México were evaluated. These compounds were analyzed by gas chromatography using capilar column and pure standards. Major volatiles such methanol, ethanol, and acetic acid were all present in each analyzed material. However, 2-methyl-propanol and 3-methyl-butanol were produced at the fermentation stage, with concentrations of 39 and $140 \mathrm{mg} \mathrm{L}^{-1}$ in A. angustifolia wort, and 40 and $121 \mathrm{mg} \mathrm{L}^{-1}$ in the $A$. potatorum wort. The volatile composition of mezcals from $A$. angustifolia and $A$. potatorum was found to be different. Mezcal from A. angustifolia had the largest quantities of methanol, higher alcohols, and acetic acid than mezcal from $A$. potatorum.

Index words: Agave angustifolia, A. potatorum, mezcal, volatile compounds.

\section{INTRODUCCIÓN}

El aroma y sabor de las bebidas alcohólicas (cerveza, vino, tequila y mezcal, entre otras), son el resultado de numerosos compuestos volátiles y no-volátiles, cuya mezcla compleja define sus atributos sensoriales y la aceptación por el consumidor (López, 1999; Vallejo y González, 1999; Cole y Noble, 2003). En el mezcal y en el tequila hay compuestos volátiles (aromáticos) en concentraciones relativamente altas (volátiles mayoritarios), principalmente metanol y alcoholes superiores (Lachenmeier et al., 2006; De León-Rodríguez et al., 2006) que son tóxicos, por lo que están regidos por las normas oficiales mexicanas NOM-070-SCFI-1994 y NOM-006-SCFI-2005. Además, contienen volátiles en concentraciones bajas (volátiles minoritarios), como ésteres, aldehídos, cetonas, ácidos, furanos y terpenos (López, 1999; López y Guevara, 2001; De LeónRodríguez et al., 2006), que contribuyen al aroma del mezcal y del tequila. Los compuestos volátiles tienen diferente origen: a) Pueden estar contenidos en la materia prima y variar entre especies, regiones geográficas y entre condiciones climáticas de cultivo; o b) Pueden generarse durante la fermentación en función de la cepa, características del mosto y condiciones del proceso, o durante la maduración del producto (Pinal et al., 1997; Cole y Noble, 2003).

En el Estado de Oaxaca se produce el mezcal de forma artesanal, bebida alcohólica que se obtiene por destilación de mostos preparados a partir de azúcares extraídos de las "cabezas" o "piñas" (tallo o eje floral con hojas cortadas) maduras y cocidas, provenientes de diferentes agaves, y 
luego sometidas a fermentación alcohólica (NOM-070SCFI-1994). Entre las especies más utilizadas destacan $A$. angustifolia por su alto volumen de producción, y $A$. potatorum (especie silvestre) por generar un mezcal de alta demanda. Debido a la naturaleza artesanal del proceso de producción del mezcal, en Oaxaca es frecuente encontrar tantos procesos como "palenques" (fabricas artesanales), lo que da lugar a diferentes calidades de materias primas y a modificaciones en los procesos, entre otros factores. La variedad de procesos influye directamente en la concentración de aromáticos en el mezcal, principalmente en los compuestos mayoritarios, como alcoholes superiores y metanol que son tóxicos en altas concentraciones; un ejemplo es el metanol que puede provocar desde ceguera hasta la muerte (Blanco et al., 2006).

En este trabajo se evaluaron los principales compuestos volátiles aromáticos mayoritarios generados durante el cocimiento, la fermentación de los mostos y en el producto final (mezcal) de las especies $A$. angustifolia y $A$. potatorum, ambos usados en sistemas artesanales de producción.

\section{MATERIALES Y MÉTODOS}

En la primavera del 2003 se seleccionaron dos fábricas ("palenques") localizadas en dos de las principales zonas productoras de Oaxaca (Tlacolula y Sola de Vega), la primera ubicada a $16^{\circ} 58^{\prime} 42^{\prime}$ ' $\mathrm{LN}$ y $96^{\circ} 32^{\prime} 11$ ' LO, a una altitud de $1660 \mathrm{~m}$, de clima templado subhúmedo con lluvias en verano; y la segunda a $16^{\circ} 30^{\prime} 13^{\prime}$ ' $\mathrm{LN}$ y $97^{\circ}$ 59' 03' ' LO, a una altitud de $1440 \mathrm{~m}$, de clima semicálido subhúmedo con lluvias en verano. En cada fábrica se hizo una descripción del proceso, se evaluaron los principales compuestos químicos presentes y los volátiles mayoritarios en el agave cocido, en el mosto durante la fermentación y en el producto final, el mezcal.

Sistema de producción de mezcal con $A$. angustifolia. En la fábrica de Tlacolula se produjo mezcal con "piñas" de $A$. angustifolia de nueve años de edad. Las "piñas" fueron cocidas durante $72 \mathrm{~h}$ en un horno de tierra rudimentario. Después de la cocción, las "piñas" frías se trituraron en un molino de piedra tipo chileno. Se colocaron $508 \mathrm{~kg}$ de agave molido en tinas de madera de encino y se dejaron reposar por $48 \mathrm{~h}$. Posteriormente, a cada tina se adicionaron $600 \mathrm{~L}$ de agua potable, se homogenizó la mezcla y se dejó fermentar 120 h más. La destilación se hizo de la forma tradicional (alambique de cobre). El destilado fue recibido en recipientes de plástico de $50 \mathrm{~L}$, y finalmente fue redestilado. El productor ajustó el grado alcohólico con agua desmineralizada hasta $40 \%$ (v/v) para su envasado.
Sistema de producción de mezcal con $A$. potatorum. En la fábrica de Sola de Vega se utilizó $A$. potatorum de nueve años de edad, con "piñas" que fueron cocidas por $48 \mathrm{~h}$ en hornos rústicos de tierra, y la molienda se hizo con mazo de madera. Una vez molido el agave, se depositaron $1002 \mathrm{~kg}$ en tinas de fermentación y se dejaron reposar durante $48 \mathrm{~h}$. Después a cada tina se agregó 850 L de agua potable, se homogenizó y fermentó durante 30 h. El mosto fermentado fue destilado en destiladores rústicos (ollas de barro). El destilado fue recibido en recipientes de 20 L y más tarde fue redestilado. Posteriormente, el productor ajustó el grado alcohólico con las "colas" (última fracción de la destilación) hasta $50 \%$ (v/v) para lograr el producto terminado a ser envasado.

\section{Muestreo y análisis químicos}

Agave cocido. Se muestrearon al azar tres "piñas" de A. angustifolia y $A$. potatorum previamente cocidas en horno de tierra. La muestra se constituyó de $50 \%$ de la base y de la hoja, y se complementó con "mezontle" (parte interna de la "piña").

Mosto (jugo fermentado). El agave molido se dejó reposar por $48 \mathrm{~h}$ en la tina de fermentación (con el proceso tradicional del mezcal); después se adicionó el agua de dilución y se homogenizó. Las muestras fueron tomadas en tres puntos de la tina a diferentes alturas y se mezclaron para formar una muestra de $1 \mathrm{~L}$; debido a las características del mosto (agave molido más agua), se utilizó una bomba casera para obtener adecuadamente la muestra del jugo fermentado. En el mosto de $A$. angustifolia la muestra se obtuvo cada $24 \mathrm{~h}$ y en el de $A$. potatorum cada $6 \mathrm{~h}$, hasta el final de la fermentación. Las muestras fueron colocadas en bolsas estériles, se separaron las del análisis microbiológico, y se colocaron en hielo frapé para su transporte al laboratorio. Las muestras para el análisis químico y cromatográfico fueron filtradas en papel filtro (Whatman ${ }^{\circledR}$ No. 4) para la eliminación del bagazo y partículas de agave; luego fueron almacenadas a $-75^{\circ} \mathrm{C}$ hasta su análisis.

Mezcal. El producto terminado con el grado alcohólico ajustado por el productor, se recolectó en frascos de vidrio de $1 \mathrm{~L}$ y se refrigeraron a $8{ }^{\circ} \mathrm{C}$. Previo a su análisis, se determinó que el extracto seco alcanzó valores muy bajos, de $0.2 \mathrm{~g} \mathrm{~L}^{-1}$, por lo que no fue necesario filtrar ni destilar.

Análisis de agave y mosto. La determinación de azúcares reductores directos se hizo por el método de Nelson (1944), la de azúcares reductores totales por el método de Dubois et al. (1956), y la de fructosa por el método de la antrona-triptófano-ácido sulfúrico (Somani 
et al., 1987). En el mosto, los sólidos solubles totales ( ${ }^{\circ}$ Brix), el pH y el nitrógeno total por Kjeldahl se determinaron por los métodos 932.14, 945.10 y 955.04 de la AOAC (1990), respectivamente. El oxígeno disuelto (OD) se evaluó con un electrodo de membrana marca Orion ${ }^{\circledR}$ Modelo 850AH previamente calibrado. El conteo total de levaduras se hizo con una cámara de Neubauerazul de metileno; una muestra de $5 \mathrm{~mL}$ adicionada con $2.5 \mathrm{~mL}$ de azul de metileno se aforó a $50 \mathrm{~mL}$ con una solución de cloruro de sodio a $0.9 \%$; de la solución se tomó una alícuota de $0.1 \mathrm{~mL}$ y se colocó en la cámara de Neubauer para contar las levaduras al microscopio.

La evaluación de los volátiles aromáticos mayoritarios en agave y mosto se hizo con un cromatógrafo de gases Perkin Elmer ${ }^{\circledR}$ provisto con detector de ionización de flama y una columna capilar HP-FFAP ${ }^{\circledR}$ de $30 \mathrm{~m}$ x 0.25 $\mathrm{mm}$; el gas acarreador fue helio, a un flujo de $1.3 \mathrm{~mL}$ $\min ^{-1}$. Se aplicó un programa de temperatura de $40{ }^{\circ} \mathrm{C}$ (por $3 \mathrm{~min}$ ) con incrementos de $3{ }^{\circ} \mathrm{C} \mathrm{min}-1$ hasta $120{ }^{\circ} \mathrm{C} \mathrm{y}$ de $6{ }^{\circ} \mathrm{C} \mathrm{min}$ min $^{-1}$ hasta $200{ }^{\circ} \mathrm{C}$ (por $20 \mathrm{~min}$ ); la temperatura del detector fue de $230{ }^{\circ} \mathrm{C}$ y la del inyector de $180{ }^{\circ} \mathrm{C}$. Para la identificación y cuantificación de los volátiles mayoritarios se utilizaron estándares de Sigma-Aldrich ${ }^{\circledR}$ y Fluka $\AA$ : etanol $99.8 \%$, metanol $99.8 \%$, alcoholes superiores (propanol $99.7 \%$, 2-metil-propanol 99.5\%, 3metil-butanol $99 \%$, pentanol $99 \%$, butanol $99.8 \%$ y 2butanol $99.5 \%$ ) y ácido acético $99.5 \%$. La curva de calibración se hizo con el método de estándar externo, con un rango de concentración de los compuestos de 1 a $1250 \mathrm{mg} \mathrm{L}^{-1}$. Todos los análisis se hicieron por triplicado. Los datos se procesaron en el programa Turbo Crhom (López y Guevara, 2001). Los datos de azúcares y volátiles mayoritarios en el mosto se graficaron mediante el programa Sigma Plot (2002).

Obtención del destilado del jugo de agave y del mosto. Se colocaron $100 \mathrm{~mL}$ de muestra $\left(\sin \mathrm{CO}_{2}\right)$ en el matraz del equipo de destilación con $50 \mathrm{~mL}$ de agua destilada; luego se calentó y el destilado se recibió en un matraz sumergido en baño de agua-hielo durante el proceso de destilación. Cuando la cantidad de destilado se acercó a la marca de aforo, se suspendió la destilación y se llevó a $20{ }^{\circ} \mathrm{C}$ para su homogenización. Para verificar la eficiencia de la destilación de la muestra, se destilaron los estándares a concentraciones conocidas bajo las mismas condiciones descritas y se analizaron por cromatografía de gases para cuantificar los compuestos; se corroboró así que hubo 100 \% de recuperación. De cada muestra destilada se inyectaron $2 \mu \mathrm{L}$ en el cromatógrafo de gases, y el área de cada pico se comparó con las curvas de calibración respectivas para determinar la concentración de cada compuesto.
En el mezcal, el grado alcohólico se determinó con el método 957.03 de la AOAC (1990). La acidez total (expresada como ácido acético), los alcoholes superiores y el metanol fueron cuantificados por cromatografía de gases. Las curvas de calibración fueron preparadas en una solución de etanol $40 \% \quad(\mathrm{v} / \mathrm{v})$ en un rango de concentración de 5 a $300 \mathrm{mg} / 100 \mathrm{~mL}$ de alcohol anhidro (NOM-006-SCFI-2005). El equipo y las condiciones utilizadas fueron similares a las descritas anteriormente con excepción de la columna, pues en este caso se utilizó una columna Megabore HP-INNOWAX® de 30 m x 0.53 mm. Para la cuantificación, se utilizó el método de estándar interno.

Análisis de la muestra de mezcal. Se colocaron $5 \mathrm{~mL}$ de acetato sec-butilo $5 \%$ (estándar interno con $99 \%$ de pureza, Sigma-Aldrich®) en un matraz de $100 \mathrm{~mL}$ y se aforó con cada mezcal destilado. Posteriormente, se tomó $1 \mu \mathrm{L}$ de la muestra preparada y se inyectó en el cromatógrafo de gases. La preparación e inyección de la muestra se hizo a $20{ }^{\circ} \mathrm{C}$. Los resultados se reportan en $\mathrm{mg} / 100$ $\mathrm{mL}$ de alcohol anhidro.

\section{RESULTADOS Y DISCUSIÓN}

pH, ${ }^{\circ}$ Brix y carbohidratos en los agaves. La composición química de los agaves varió entre especies y por las condiciones del horno de cocimiento; en $A$. angustifolia el $\mathrm{pH}$ fue de 4.5 con $27^{\circ}$ Brix mientras que en $A$. potatorum el pH fue 5.5 con $22{ }^{\circ}$ Brix. En el Cuadro 1 se muestra que $A$. angustifolia superó a $A$. potatorum en contenido de azúcares totales, fructosa y azúcares reductores directos.

Compuestos volátiles en los jugos de agaves cocidos. En los agaves cocidos se identificaron cuatro compuestos volátiles: metanol, etanol, ácido acético y pentanol (Cuadro 1). La concentración de metanol fue mayor en $A$. angustifolia que en $A$. potatorum, diferencia que se atribuyó a la especie de agave; es probable que ello se deba a la desmetilación de pectinas de los agaves por efecto de las temperaturas altas y del pH ácido (Téllez, 1998). Las concentraciones de ácido acético y etanol fueron mayores en $A$. Angustifolia que en $A$. potatorum; es probable que el ácido acético se haya originado en la reacción de Maillard durante el cocimiento, ya que es un compuesto identificado en exudados de Agave tequilana Weber (Mancilla-Margalli y López, 2002). La reacción de Maillard es común en alimentos cocidos y produce oscurecimiento no enzimático, debido al ataque nucleofílico del grupo amino de un aminoácido a un grupo carbonilo de un carbohidrato (reacción de Amadori), y es seguida de una cascada de reacciones que generan compuestos volátiles muy aromáticos que tienen gran impacto en el 
sabor del producto final (Scarpellino y Soukup, 1993). La presencia de etanol fue una clara consecuencia de la fermentación de los azúcares por las levaduras presentes durante el enfriado de las "piñas" cocidas. Las concentraciones de pentanol fueron similares en ambas especies.

Cuadro 1. Azúcares y compuestos volátiles en A. angustifolia y A. potatorum.

\begin{tabular}{lcc}
\hline Compuesto & A. angustifolia & A. potatorum \\
\hline Azúcares & & \\
Azúcares totales $\left(\mathrm{mg} \mathrm{g}^{-1}\right)$ & $544.0 \pm 1.14$ & $259.4 \pm 57.50$ \\
Fructosa $\left(\mathrm{mg} \mathrm{g}^{-1}\right)$ & $524.0 \pm 0.49$ & $260.0 \pm 85.70$ \\
Azúcares reductores directos & $185.0 \pm 2.25$ & $140.8 \pm 48.00$ \\
$\left(\mathrm{mg} \mathrm{g}^{-1}\right)$ & & \\
Compuestos volátiles & & \\
Metanol $\left(\mathrm{mg} \mathrm{L}^{-1}\right)$ & $319.0 \pm 4.82$ & $172.0 \pm 0.32$ \\
Ácido acético (mg L & & \\
Etanol $\left(\mathrm{mg} \mathrm{L}^{-1}\right)$ & $143.0 \pm 11.71$ & $284.0 \pm 13.42$ \\
Pentanol $\left(\mathrm{mg} \mathrm{L}^{-1}\right)$ & $1.5 \pm 0.05$ & $90.0 \pm 0.81$ \\
& & $2.4 \pm 0.02$ \\
\hline
\end{tabular}

Composición química de los mostos. Ambos mostos presentaron un aumento de temperatura (Cuadro 2), debido a la liberación de energía de la actividad metabólica de las levaduras durante la fermentación (Delfini y Formica, 2001). El mosto de A. Angustifolia presentó mayores valores de temperatura, oxígeno inicial, azúcares, ${ }^{\circ}$ Brix y la relación $\mathrm{C} / \mathrm{N}$, pero nitrógeno y $\mathrm{pH}$ fueron mayores en $A$. potatorum. El pH cambió durante la fermentación, probablemente por la presencia de ácidos orgánicos cómo el ácido acético generado por la fermentación acética de las bacterias Acetobacter a través del metabolismo de etanol a acetaldehído y ácido acético (Bartowsky y Henschke, 2008). Las concentraciones iniciales de oxígeno disuelto en los mostos fueron menores a las reportadas por Casey et al. (1984) para el crecimiento de levaduras, lo que influyó en la población de microorganismos presentes, ya que el oxígeno es importante para la síntesis de lípidos y ácidos grasos insaturados de la membrana plasmática de las levaduras, lo que permite mejorar la actividad fermentativa (Salmon, 2006).

La mayor concentración de nitrógeno en el mosto de $A$. potatorum provocó una menor proporción de $\mathrm{C} / \mathrm{N}$, lo cual influyó en un aumento en el número de levaduras, de 4.2 x $10^{7}$ a $9.8 \times 10^{7}$ cél. $\mathrm{mL}^{-1}$ a las $54 \mathrm{~h}$ de fermentación, que superó a las de A. angustifolia que fueron de $1.6 \mathrm{x}$ $10^{7}$ a $2.5 \times 10^{7}$ cél. $\mathrm{mL}^{-1}$ a las $96 \mathrm{~h}$. Sin embargo, el número de levaduras en estas fermentaciones fue bajo comparado con los reportados para tequila en condiciones rústicas, donde la población alcanza valores de 6 a $15 \mathrm{x}$ $10^{7}$ cél. $\mathrm{mL}^{-1}$ (Cedeño, 1995) o en condiciones controladas de $2 \times 10^{7}$ cél. $\mathrm{mL}^{-1}$ (Arrizon y Gschedler, 2006; Arrizon y Gschedler, 2002).
Cuadro 2. Características físicas y químicas de los mostos de $A$. angustifolia y A. potatorum $(\mathrm{n}=3)$.

\begin{tabular}{lrr}
\hline Características & $\begin{array}{c}\text { Mosto de } \\
\text { A. angustifolia }\end{array}$ & $\begin{array}{c}\text { Mosto de } \\
\text { A. potatorum }\end{array}$ \\
\hline Temperatura inicial $\left({ }^{\circ} \mathrm{C}\right)$ & $25.3 \pm 0.10$ & $18.6 \pm 0.10$ \\
Temperatura final $\left({ }^{\circ} \mathrm{C}\right)$ & $32.8 \pm 0.10$ & $29.8 \pm 0.10$ \\
pH inicial & $4.2 \pm 0.10$ & $4.5 \pm 0.10$ \\
pH final & $4.0 \pm 0.10$ & $4.3 \pm 0.10$ \\
$\mathrm{O}_{2}$ inicial $\left(\mathrm{mg} \mathrm{L}^{-1}\right)$ & $0.25 \pm 0.03$ & $0.14 \pm 0.01$ \\
Azúcares reductores totales & $77.1 \pm 1.85$ & $53.2 \pm 0.35$ \\
$\left(\mathrm{~g} \mathrm{~L}^{-1}\right)$ inicial & $70.3 \pm 0.88$ & $50.9 \pm 0.83$ \\
$\begin{array}{l}\text { Azúcares reductores directos } \\
\left.(\mathrm{g} \mathrm{L})^{-1}\right) \text { inicial }\end{array}$ & & \\
Solidos totales $\left({ }^{\circ}\right.$ Brix) & $9.0 \pm 0.20$ & $8.1 \pm 0.20$ \\
$\begin{array}{l}\text { Concentración de nitrógeno } \\
\left.(\mathrm{mg} \mathrm{L})^{-1}\right)\end{array}$ & $209.2 \pm 10.78$ & $403.3 \pm 2.37$ \\
$\mathrm{C} / \mathrm{N}$ & 0.368 & \\
\hline
\end{tabular}

En azúcares reductores totales residuales los valores fueron de $28.3 \mathrm{~g} \mathrm{~L}^{-1}$ en el mosto de $A$. angustifolia, y de $23.19 \mathrm{~g} \mathrm{~L}^{-1}$ en el de $A$. potatorum (Figura 1); tales valores sugieren que la hidrólisis de carbohidratos no fue completa durante la cocción, atribuible a que se utilizaron hornos rústicos sin control de temperatura, a diferencia de los hornos con vapor utilizados en la industria del tequila, en donde hay $98 \%$ de eficiencia en la hidrólisis (Waleckx et al., 2008).

Producción de etanol, metanol y alcoholes superiores en los mostos. Las producciones máximas de etanol fueron de $8.1 \%(\mathrm{v} / \mathrm{v})$ a las $168 \mathrm{~h}$ en $A$. angustifolia y de $5.5 \%(\mathrm{v} / \mathrm{v})$ a las $72 \mathrm{~h}$ en $A$. potatorum, la que bajó ligeramente a $5.0 \%(\mathrm{v} / \mathrm{v})$ al final de la fermentación $(80$ h) (Figura 1). La diferencia en la concentración final de etanol alcanzada puede ser por la diferencia en azúcares reductores totales iniciales y por las pérdidas de etanol debidas a 1a generación de ácido acético o a su evaporación, como en el mosto de $A$. potatorum cuya concentración de etanol bajó en $0.5 \%$. La productividad mayor de etanol en el mosto de $A$. angustifolia $\left(0.446 \mathrm{~g} \mathrm{~L} \mathrm{~h}^{-1}\right)$ con respecto a la del $A$. potatorum $\left(0.593 \mathrm{~g} \mathrm{~L} \mathrm{~h}^{-1}\right)$, puede ser explicada por diferencias en las concentraciones de azúcares totales y de nitrógeno (Cuadro 2), que se ve reflejada en una mayor relación $\mathrm{C} / \mathrm{N}$ en el mosto de $A$. angustifolia (0.37) que en el de $A$. potatorum (0.13).

Entre especies no hubo una diferencia considerable en la concentración de metanol producido, que fueron de 111 $\mathrm{mg} \mathrm{L}^{-1}$ y $108 \mathrm{mg} \mathrm{L}^{-1}$ en $A$. angustifolia y $A$. potatorum, respectivamente. Sin embargo, al inicio de la fermentación ya existía más de $50 \%$ de metanol en ambos mostos (Figura 2), lo cual se confirma con los resultados obtenidos en jugos de agaves cocidos (Cuadro 1), y con lo reportado para tequila en donde se forma una fracción de metanol durante el cocimiento (Téllez, 1998), y el resto durante la fermentación debido a la acción de microorganismos con actividad pectinolítica que 
hidrolizan las pectinas y producen metanol (Cedeño, 1995).

Los alcoholes superiores aumentaron gradualmente durante la fermentación; en el mosto de $A$. angustifolia la producción de 2-metil-1-propanol y 3-metil-1-butanol fue de 39 y $140 \mathrm{mg} \mathrm{L}^{-1}$, y en $A$. potatorum fue de 40 y 121 $\mathrm{mg} \mathrm{L}^{-1}$, respectivamente (Figura 2 ). La diferencia en 3metil-1-butanol puede ser debida a las diferencias en la relación $\mathrm{C} / \mathrm{N}$ en los mostos. Estos resultados son similares a los de Pinal et al. (1997) y Arrizon y Gschedler (2006), quienes en tequila encontraron que una alta relación $\mathrm{C} / \mathrm{N}$ produce mayor concentración de alcoholes superiores como resultado de las reacciones de desaminación de aminoácidos, y probablemente porque las cadenas de carbono favorecen la síntesis de alcoholes superiores (Walker, 2000; Delfini y Formica, 2001).

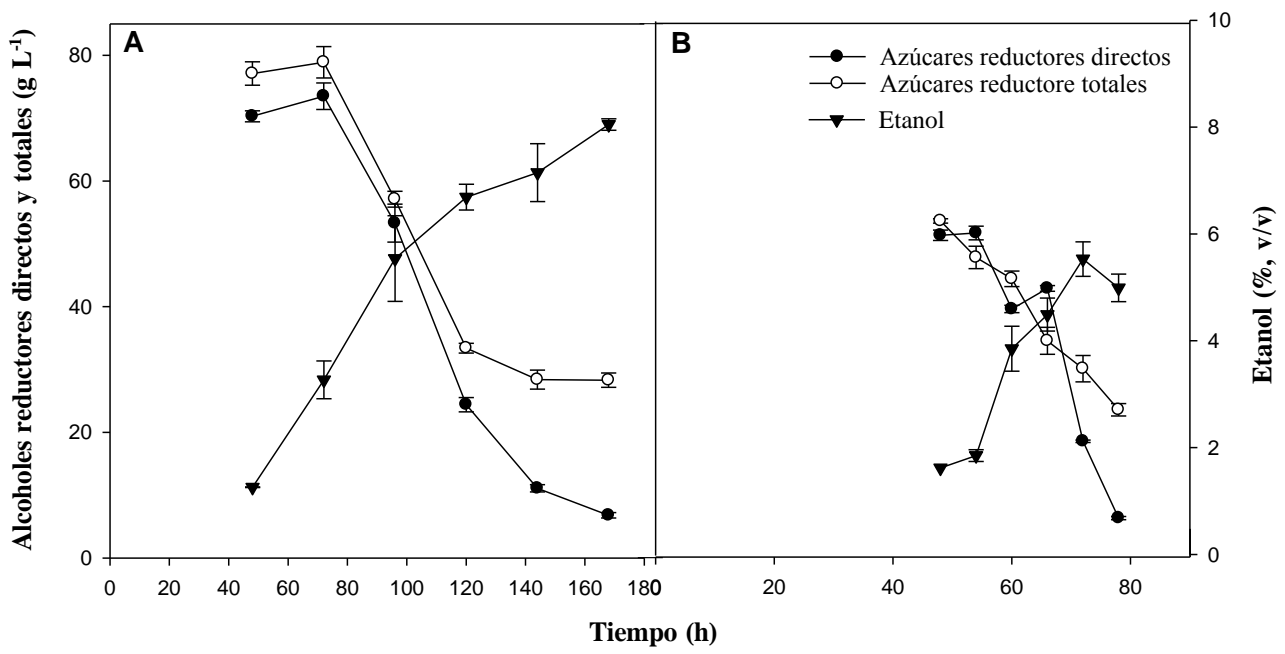

Figura 1. Consumo de azúcares y formación de etanol durante la fermentación del mosto de $\boldsymbol{A}$. angustifolia Haw. (A) y A. potatorum Zucc. (B). Las barras verticales representan el error estándar $(\mathbf{n}=3)$.

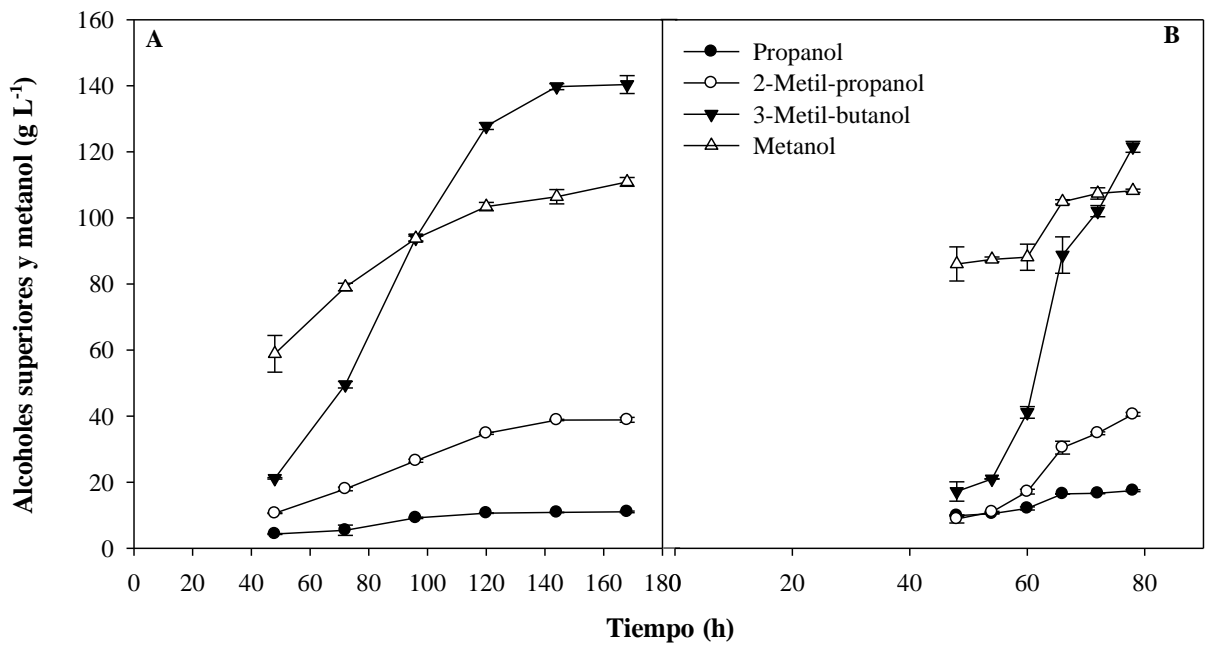

Figura 2. Formación de alcoholes superiores y metanol durante la fermentación de mostos de $A$. angustifolia Haw. (A) y A. potatorum Zucc. (B). Las barras verticales en cada punto representan el error estándar $(\mathbf{n}=\mathbf{3})$. 
De n-propanol hubo menor concentración en el mosto de $A$. angustifolia $\left(11 \mathrm{mg} \mathrm{L}^{-1}\right)$ que en el de $A$. potatorum $\left(17 \mathrm{mg} \mathrm{L}^{-1}\right)$, lo que correlacionó positivamente $(\mathrm{r}=$ $0.89^{*}$ ) con el contenido de nitrógeno, 211 y $403 \mathrm{mg} \mathrm{L}^{-1}$, en los mostos. Este comportamiento coincide con lo reportado en la fermentación de mostos de uva (Ough y Bell, 1980) y de tequila, en los que la concentración de este compuesto aumentó con la adición de sulfato de amonio y aminoácidos (Arrizon y Gschedler, 2006). Otros alcoholes superiores detectados fueron n-butanol y n-pentanol, de los cuales solamente hubo trazas $(<1 \mathrm{mg}$ $\mathrm{L}^{-1}$ ) en el mosto de $A$. angustifolia y no los hubo en $A$. potatorum. La baja concentración o ausencia de n-butanol depende de las especies de levaduras presentes en la fermentación (Díaz-Montaño et al., 2008). En mezcal y tequila se han reportado muy bajas concentraciones de butanol $(0.75$ a $3.25 \mathrm{mg} / 100 \mathrm{~mL}$ de alcohol anhidro) (Lachenmeier et al., 2006). El ácido acético presentó mayor concentración en el mosto de A. angustifolia (587 $\mathrm{mg} \mathrm{\textrm {L } ^ { - 1 }}$ ) que en el de $A$. potatorum $\left(213 \mathrm{mg} \mathrm{L}^{-1}\right)$, probablemente como consecuencia de las diferencias en los tiempos de fermentación, que conlleva el riesgo de contaminación por bacterias acéticas; estas bacterias se adaptan fácilmente a ambientes ricos en azúcar y etanol en presencia de oxígeno (Bartowsky y Henschke, 2008).

Volátiles mayoritarios en el mezcal. Los compuestos etanol, metanol y alcoholes superiores que ocurren en las bebidas alcohólicas destiladas, se producen en mayor concentración y por su alto grado de toxicidad están regidos por las Normas Oficiales Mexicanas. En mezcal se rige por la NOM-070-SCFI-Mezcal-Bebidas alcohólicas. La determinación de grado alcohólico, metanol, alcoholes superiores y acidez total (como ácido acético) del mezcal proveniente de $A$. angustifolia y $A$. potatorum (Cuadro 3), permitieron calificar el cumplimiento con la norma. Las muestras de mezcal fueron diferentes en composición química; el mezcal de $A$. angustifolia presentó mayores contenidos de metanol, alcoholes superiores y ácido acético que el de $A$. potatorum que sólo destacó por su mayor contenido de etanol.

Estas diferencias observadas dependieron de la especie de agave, de las condiciones del proceso de elaboración, principalmente durante la fermentación cuando se produce la mayoría de compuestos volátiles (Díaz-Montaño et $a l ., 2008)$, y de la técnica de destilación empleada al momento de hacer los cortes de las principales fracciones "puntas" (primera fracción destilada), "cuerpo" (segunda fracción) y "colas" (tercera fracción), ya que la mayor concentración de alcoholes superiores se encuentra en las "puntas" y disminuye conforme transcurre la destilación, a diferencia del metanol y del ácido acético que se van incrementando y alcanzan su mayor concentración en las "colas". La concentración de estos alcoholes debe vigilarse debido a que en el sistema tradicional del mezcal aún no esta estandarizada su destilación, sino que depende del criterio del productor. Los parámetros de grado alcohólico, metanol y alcoholes superiores de estos mezcales cumplieron en su totalidad los intervalos establecidos por la Norma Oficial Mexicana (Cuadro 3). Sin embargo, el contenido de ácido acético del mezcal de $A$. angustifolia sobrepasó el límite máximo permitido. Este alto contenido de ácido acético tuvo una relación directa con la cantidad generada durante la fermentación, y con la técnica de destilación empleada.

\section{CONCLUSIONES}

En mezcal los volátiles mayoritarios, metanol, etanol y ácido acético, aparecen desde la cocción; el 2-metilpropanol y 3-metil-butanol desde la fermentación y todos permanecen hasta el producto final (mezcal). La producción de compuestos volátiles aromáticos mayoritarios difiere entre especies de agave y entre condiciones de fermentación.

Cuadro 3. Compuestos volátiles permitidos por la NOM-070-SCFI-1994-Bebidas alcohólicas-Mezcal-Especificaciones $(\mathbf{n}=3)$.

\begin{tabular}{|c|c|c|c|}
\hline Compuesto & $\begin{array}{c}\text { A. angustifolia } \\
\text { (mg/100 mL de alcohol } \\
\text { anhidro) }\end{array}$ & $\begin{array}{c}\text { A. potatorum } \\
\text { (mg/100 mL de alcohol } \\
\text { anhidro) }\end{array}$ & Norma $^{\dagger \dagger \dagger}$ \\
\hline Grado alcohólico \% (v/v) a $20{ }^{\circ} \mathrm{C}^{\dagger \dagger}$ & $40.0 \pm 0.28$ & $50.0 \pm 0.16$ & $36-55$ \\
\hline Metanol & $242.0 \pm 12.40$ & $178.0 \pm 2.62$ & $100-300$ \\
\hline Acidez total (como ácido acético) & $350.0 \pm 13.02$ & $90.0 \pm 0.61$ & $0-170$ \\
\hline \multicolumn{4}{|l|}{ Alcoholes superiores: } \\
\hline 2-Butanol & $2.1 \pm 0.08$ & $0.75 \pm 0.01$ & \\
\hline Propanol & $27.0 \pm 1.67$ & $36.0 \pm 0.51$ & \\
\hline 2-Metil-1-propanol & $93.0 \pm 2.69$ & $65.0 \pm 0.91$ & \\
\hline Butanol & $1.0 \pm 0.05$ & $1.2 \pm 0.02$ & \\
\hline 3-Metil-1-butanol & $266.0 \pm 8.53$ & $182.0 \pm 1.51$ & \\
\hline Total & 389.00 & 285.00 & $100-400$ \\
\hline
\end{tabular}

${ }^{\dagger}$ Sólo este componente se presenta en $\%(\mathrm{v} / \mathrm{v})$

${ }^{\dagger \dagger}$ NOM-070-SCFI-1994-Bebidas Alcohólicas-Mezcal-Especificaciones. 
En los jugos de agave cocido las concentraciones de metanol, etanol, ácido acético y azúcares reductores fueron mayores en $A$. angustifolia que en $A$. potatorum. El mosto de $A$. angustifolia presentó mayor relación $\mathrm{C} / \mathrm{N}$ que el de $A$. potatorum, lo que se reflejó en la producción etanol de ambos casos. La especie de agave no influyó en la producción de metanol, 2-metil-1-propanol y 3-metil-1butanol, ya que sus concentraciones fueron similares en ambos mostos, a diferencia del propanol que se encontró en menor concentración en el mosto de $A$. angustifolia. La concentración de ácido acético en el jugo de agave cocido, mosto y el producto final de $A$. angustifolia fue mayor que la de $A$. potatorum. Los volátiles aromáticos mayoritarios presentes en la fermentación permanecieron en la misma proporción en el producto terminado en las dos especies de agave. Los mezcales de ambas especies cumplieron en su totalidad con los intervalos establecidos por la Norma Oficial, aunque la composición química de las muestras de mezcal fueron diferentes entre sí. El alto contenido de ácido acético en el mezcal de $A$. angustifolia tuvo una relación directa con la cantidad generada durante el cocimiento y la fermentación.

\section{AGRADECIMIENTOS}

Al Quím. Uriel Terán Sangerman por su colaboración en el trabajo de laboratorio, al Dr. Pedro Benito Bautista por las facilidades otorgadas en la realización del trabajo, a la Dra. Yolanda Donají Hernández Ortiz por la revisión del manuscrito, a los productores de mezcal de Tlacolula y Sola de Vega, y al SIBEJ-CONACyT y al Instituto Politécnico Nacional por el financiamiento del proyecto.

\section{BIBLIOGRAFÍA}

Arrizon J, A Gschaedler (2002) Increasing fermentation efficiency at high sugar concentrations by supplementing an additional source of nitrogen during the exponential phase of the tequila fermentation process. Can. J. Microbiol. 48:965-970.

Arrizon J, A Gschaedler (2006) Effects of the addition of different nitrogen sources in the tequila fermentation process at high sugar concentration. J. Appl. Microbiol. 102:1123-1131.

Bartowsky E J, P A Henschke (2008) Acetic acid bacteria spoilage of bottled red wine. Internatl. J. Food Microbiol. 125:60-70.

Blanco M, R Casado, F Vásquez, J M Pumar (2006) CT y MR imaging findings in methanol intoxication. Amer. J. Neuroradiol. $27: 452-454$

AOAC (1990) Official methods of analysis of the Association of Official Analytical Chemists. Vol. 2, 15th ed., Association of Official Analytical Chemist, Washington DC, USA. pp: 692, 735, 915.

Casey G P, C A Magnus, W M Ingledew (1984) High gravity brewing: effects of nutrition on yeast composition, fermentative ability, and alcohol production. Appl. Environ. Microbiol. 48:639646.

Cedeño C M (1995) Tequila production. Crit. Rev. Biotechnol. 15:111 .
Cole V C, A C Noble (2003) Flavor chemistry. In: Fermented Beverage Production. A G H Lea, J R Piggott (eds). Kluwer Academic/ Plenum Publishers New York. pp:393-396.

Delfini C, J Formica (2001) Wine Microbiology: Science and Technology. Marcel Dekker, Inc. Italy. pp:266, 339.

De León-Rodríguez A, L González-Hernández, A P Barba de la Rosa, P Escalante-Minakata, M G López (2006) Characterization of volatile compounds of mezcal, an ethnic alcoholic beverage obtained from Agave salmiana. J. Agric. Food Chem. 54:13371341

Díaz-Montaño D M, M L Delia, M Estarrón-Espinoza, P Strehaiano (2008) Fermentative capability and aroma compound production by yeast Straits isolated from Agave tequilana Weber juice. Enz. Microbial Technol. 42:608-616.

Dubois M, K A Gilles, J K Hamilton, P A Reber, F Smith (1956) Colorimetric method for determination of sugars and related substances. Analyt. Chem. 28:350-356.

Lachenmeier D W, E M Sohnius, R Attig, M G López (2006) Quantification of selected volatile constituents and anions in mexican Agave spirits (tequila, mezcal, sotol and bacanora). J. Agric. Food Chem. 54:3911-3915.

López M G (1999) Tequila Aroma. In: Flavor Chemistry of Ethnic Foods. F Shahidi, Ch Ho (eds). Kluwer Academic/Plenum Publishers, New York. pp:211-217.

López M G, Y Guevara (2001) Authenticity of three mexican alcoholic beverages by SPME-GCMS. Annual Meeting of Institute of Food Technologists, New Orleans, LA. pp:10-3.

Mancilla-Margalli N, M G López (2002) Generation of Maillard compounds from inulin during the thermal processing of Agave tequilana Weber Var. azul. J. Agric. Food Chem. 50:806-812.

Nelson J A (1944) A photometric adoption of the Somogyi method for the determination of glucose. J. Biol. Chem. 153:375-380.

Norma Oficial Mexicana (1997) NOM-070-SCFI-1994, "Bebidas Alcohólicas-Mezcal-Especificaciones”. Disponible en: www.economia.gob.mx (Septiembre. 2009).

Norma Oficial Mexicana (2006) NOM-006-SCFI-2005, "Bebidas Alcohólicas-Tequila-Especificaciones”. Disponible en: www.economia.gob.mx (Septiembre 2009).

Ough C S, A A Bell (1980) Effects of nitrogen fertilization of grape wines on amino acid metabolism and higher-alcohol formation during grape juice fermentation. Amer. J. Enol. Vitic. 31:122-123.

Pinal L, M Cedeño, H Gutiérrez, J Álvarez (1997) Fermentation parameters influencing higher alcohol production in the tequila process. Biotechnol. Lett. 19:45-47.

Salmon M J (2006) Interactions between yeast, oxygen and polyphenols during alcoholic fermentations: Practical implications. LWT-Food Sci. Technol. 39:959-965.

Scarpellino R, R J Soukup (1993) Key flavors from heat reactions of food ingredients. In: Flavor Science. T E Acree, R Teranishi (eds) American Chemical Society, Washington, DC pp:309-333.

Sigma Plot (2002) Sigma Plot for Windows version 8.0. SPSS Inc. UK.

Somani B L, J Khanade, R Sinha (1987) A modified anthronesulphuric acid method for the determination of fructose in the presence of certain proteins. Analyt. Biochem. 167:327-330.

Téllez P (1998) El cocimiento una etapa importante en la producción de tequila. Bebidas Mex. 7:19-20.

Vallejo C, C González (1999) Identificación de los compuestos volátiles del tequila. Bebidas Mex. 8:1-17.

Walker G M (2000) Yeast Physiology and Biotechnology. Wiley and Sons. London. pp: 52, 244, 245.

Waleckx E, A Gschaedler, B Colonna-Ceccaldi, M Pierre (2008) Hydrolysis of fructans from Agave tequilana Weber var. azul during the cooking step in a traditional tequila elaboration process. Food Chem. 108:40-48. 